\title{
Comparison of drug-eluting balloon versus drug-eluting stent for treatment of coronary artery disease: a meta-analysis of randomized controlled trials
}

\author{
Lulu Liu, Bin Liu, Jiajun Ren, Gang Hui, Chao Qi and Junnan Wang* ${ }^{*}$
}

\begin{abstract}
Background: Drug-eluting balloons (DEB) have significant value for treating coronary artery disease (CAD). However, the merits of using DEB versus drug-eluting stents (DES) to treat CAD remain controversial. Herein, we conducted a meta-analysis to compare the safety and efficacy of DEB and DES for treatment of CAD.

Methods: We searched MEDLINE, EMBASE, and CENTRAL databases for eligible trials comparing DEB with DES for treatment of CAD. The primary endpoint was major adverse cardiac events (MACE); the secondary endpoints included in-lesion late lumen loss (LLL), binary restenosis (BR), myocardial infarction (MI), target lesion revascularization (TLR) and mortality.

Results: Twenty-three trials with a total of 2712 patients were included. There were no significant differences in the primary endpoint of MACE between the DEB and DES groups (Risk Ratio (RR) 1.19; 95\% confidence interval (CI) $(0.87,1.63) ; P=0.27)$, or in the clinical outcomes of each of MACE's components, including TLR, MI and mortality. However, efficacy was significantly different between the DEB and DES groups, especially when we compared DEB to second-generation DES: in-lesion LLL (Mean Difference (MD) 0.11; (0.01, 0.22); $P=0.03$ ); binary restenosis (RR 1.46; $(1.00,2.13) ; P=0.05)$.
\end{abstract}

Conclusions: DEB is equivalent to DES in terms of safety for managing CAD, and DEB may be considered as an alternative choice for treatment of CAD.

Keywords: Coronary artery disease, Drug-eluting balloon, Drug-eluting stent, Meta-analysis

\section{Background}

Coronary interventional therapy has significantly improved the prognosis of patients with CAD $[1,2]$. In particular, the clinical application of drug eluting stents (DES) has greatly reduced the occurrence rate of in-stent restenosis (ISR), which is one of the major complications associated with bare metal stents (BMS) [3]. However, there are still several DES-linked potential complications, such as delayed vascular endothelial healing, late and very late stent malapposition and stent thrombosis, and emerging atherosclerosis $[4,5]$. In addition, DES is not effective at treating some complex coronary artery lesion subsets,

\footnotetext{
* Correspondence: jdeywjn@163.com

Department of Cardiology, Second Hospital of Jilin University, No. 218 Ziqiang Street, Changchun 130041, China
}

such as small vessel disease (SVD) (defined as target vascular lesions at both ends of the reference diameter $\leq$ $2.75 \mathrm{~mm}$ ) [6] and bifurcation [7], suggesting that DES is not optimal for certain CAD. Besides, diabetic patients with coronary artery stenosis have worse clinical outcomes including mortality and repeated revascularization which related to in-stent restenosis and stent thrombosis $[8,9]$. Hence, it is imperative to devise a new treatment strategy which may offer effective treatment while reducing complications for those "difficult" CAD cases.

Based on the above-mentioned limitations of DES, DEB was designed to avoid insertion of a permanent foreign object in the blood vessel, and therefore prevent potential problems caused by DES [10]. DEBs are coated with a thin mixture of pharmacologically active, 
high dose anti-proliferative drugs on the base of an ordinary balloon. The drugs are transferred to the neointimal layer of the vascular wall upon a single inflation of the balloon, which typically takes a maximum of 30-60 s in coronary intervention [11-13]. To circumvent the elastic recoil that occurs after DEB inflation, a bare metal stent (BMS) is subsequently employed [14].

However, the superiority of either DES or DEB for treating coronary stenosis remains unknown. Therefore, we performed this meta-analysis to compare the advantages and disadvantages of DEB (in combination with BMS or as a stand-alone therapy) and DES in the treatment of $\mathrm{CAD}$ and systematically reviewed the safety and efficacy of DEB in clinical applications.

\section{Methods}

\section{Search strategy}

Two independent investigators (Lulu Liu and Jiajun Ren) searched the MEDLINE, EMBASE and CENTRAL databases. We also considered published review articles, editorials, and internet-based sources of information ((http://www.tctmd.com), (http://www.europcronline.com) and (http://www.crtonline.org)) to assess potential information on trials of interest. Conferences from the American Heart Association and American College of Cardiology were reviewed as well. The study was performed according to the Preferred Reporting Items for Systematic Reviews and Meta-analyses (PRISMA) guidelines for meta-analyses of randomized trials [15]. The search end date was September 4th, 2017. The search keywords were ("drugeluting balloon" OR "drug coated balloon") AND ("drugeluting stent" OR "drug coated stent") AND ("randomized controlled trial" OR "controlled clinical trial") NOT ("popliteal" OR "femoropopliteal" OR "infrapopliteal" OR "infrainguinal"). The detailed search strategy is shown in Additional file 1. Trials were limited to human trials. The selection process was conducted with the titles and abstracts of all citations to identify potentially relevant trials. Then, the corresponding publications were reviewed in the full text to assess if trials met the inclusion criteria. The selection process and data extraction were completed by the two investigators independently. When there was no agreement between the two reviewers, a third person was involved to discuss the situation and make the final decision.

\section{Selection criteria and interest of endpoints}

Trials that had all of the following were included in the analysis: (1) randomized controlled trials (RCT); (2) subjects in the study had CAD; and (3) the intervention measure of the study involved DEB and DES. Trials that had one or more of the following were excluded from the analysis: (1) non-RCT, such as observational trials or retrospective trials; (2) incomplete or having statistical differences of baseline data; and (3) no available full text. The primary endpoint was major adverse cardiac events (MACE). The secondary endpoints were in-lesion late lumen loss (LLL) (calculated as the difference of in-stent minimal lumen diameter (MLD) between measurements immediately after the procedure and at follow-up) [16], binary restenosis (BR) (defined as diameter stenosis > $50 \%$ by quantitative coronary angiography (QCA) at the follow-up angiogram) [17], and the components of MACE (myocardial infarction (MI), target lesion revascularization (TLR), and mortality). Clinical outcomes were considered safety outcomes, such as MACE and each of its components, whereas procedural outcomes, including LLL and $\mathrm{BR}$, were considered efficacy outcomes.

\section{Data extraction and quality assessment}

We extracted study information, such as baseline characteristic data, major endpoints, number of patients, type of disease, and other related information, from the selected trials, and then summarized the data in a prepared standardized extraction database (Microsoft EXCEL). We used the RCT Document Quality Evaluation Criteria recommended by the Cochrane Handbook 5.1.0 [18] to assess the quality of included trials based on the following points: sequence generation, allocation concealment, blinding of participants and personnel, blinding of outcome assessment, incomplete outcome data, selective outcome reporting and 'other issues'. A study was judged using the labels 'low risk', 'high risk' or 'unclear risk'.

\section{Statistical analysis}

For comparison of the dichotomous and continuous data, risk ratio (RR) and mean difference (MD) and their 95\% confidence intervals (CI) were used as the effect indicators. Mantel-Haenszel method was used for combining RRs, and the overall MD was built with the inverse variance method as recommended [19]. $P \leq 0.05$ was considered statistically significant for overall effect. Statistical analysis was performed using the Review Manager 5.3 software (The Nordic Cochrane Centre, The Cochrane Collaboration, Copenhagen, Denmark). The heterogeneity of the included trials was analyzed by Chi-squared test and $\mathrm{I}^{2}$ statistic based on the Mantel-Haenszel random-effects model for combining RRs or Inverse Variance random-effects model for MD. The test level was set to $\alpha=0.1$, in combination with $\mathrm{I}^{2}$ to access the heterogeneity quantitatively, and $\mathrm{I}^{2}>50 \%$ was regarded as being indicative of moderate-to-high heterogeneity [20]. A $P$ value $\geq 0.1$ suggested that there was no statistical heterogeneity among the results. We then used the fixed effect model for meta-analysis, and $P<0.1$ suggested that there was statistical heterogeneity among the results. In this case, we used the random 
effect model for the meta-analysis [21, 22]. Analyses were carried out for overall coronary artery conditions and then stratified by the method of treatments and type of lesions, or on the basis of factors that may lead to heterogeneity, such as different generations of DES and follow-up length. Sensitivity analysis was performed by removing the results of individual trials one by one to observe the changes in effect size. We used Begger Funnel plot and Egger tests with Stata (version $12.0)$ to assess publication bias, with a $P$ value $<0.05$ was considered statistically significant.

\section{Results}

The study flow chart was established using PRISMA (Fig. 1). The initial search result collected 3013 publications. By excluding the repetition in the literature and applying the inclusion and exclusion criteria, 55 full text papers were reviewed and 23 articles were finally included, which included a total of 2712 patients [23-45]. The angiographic follow-up period was 6 to 12 months, and the clinical follow-up period ranged from 6- to 36months. The types of CAD reported in the literature included seven simple coronary lesions [23-29], seven ISR
[30-36], two bifurcated lesions [40, 41], two small vessel disease (SVD) [37, 38], and one diabetes-linked coronary artery stenosis [39]. All trials were RCT, four of which were 3-year follow-ups of PEPCAD II [42], BELLO [43], ISAR-DESIRE 3 [44], and RIBS V [45]. The study population included patients who were recruited from the beginning of the study without any abnormal clinical characteristics, and were only described the clinical data after 3 years of follow-up. We extracted the number of patients, the types of DEB and DES, follow-up time, dual anti platelet therapy (DAPT) duration, and other information needed for this analysis from each study. The baseline characteristic data between the DEB and DES groups are summarized in Table 1, and more baseline clinical data are summarized in Additional file 2. There were no significant differences between these two groups with regards to baseline characteristics of the patients. The risk of bias assessment of included trials is shown in Fig. 2.

\section{Primary endpoints \\ Mace}

There was no statistical difference in MACE between the DEB and DES groups (RR $1.19(0.87,1.63) ; P=0.27$,

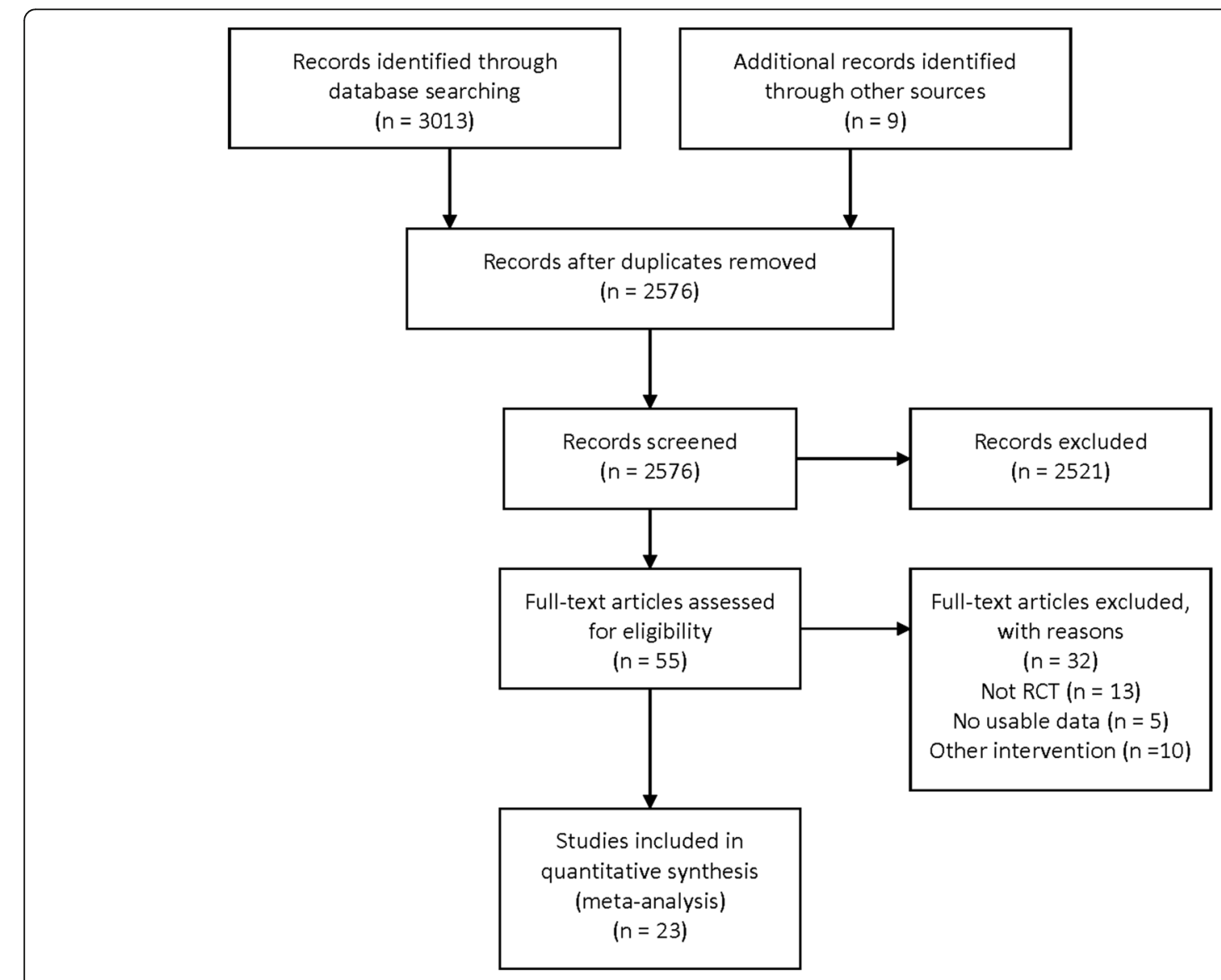

Fig. 1 Search flow diagram 


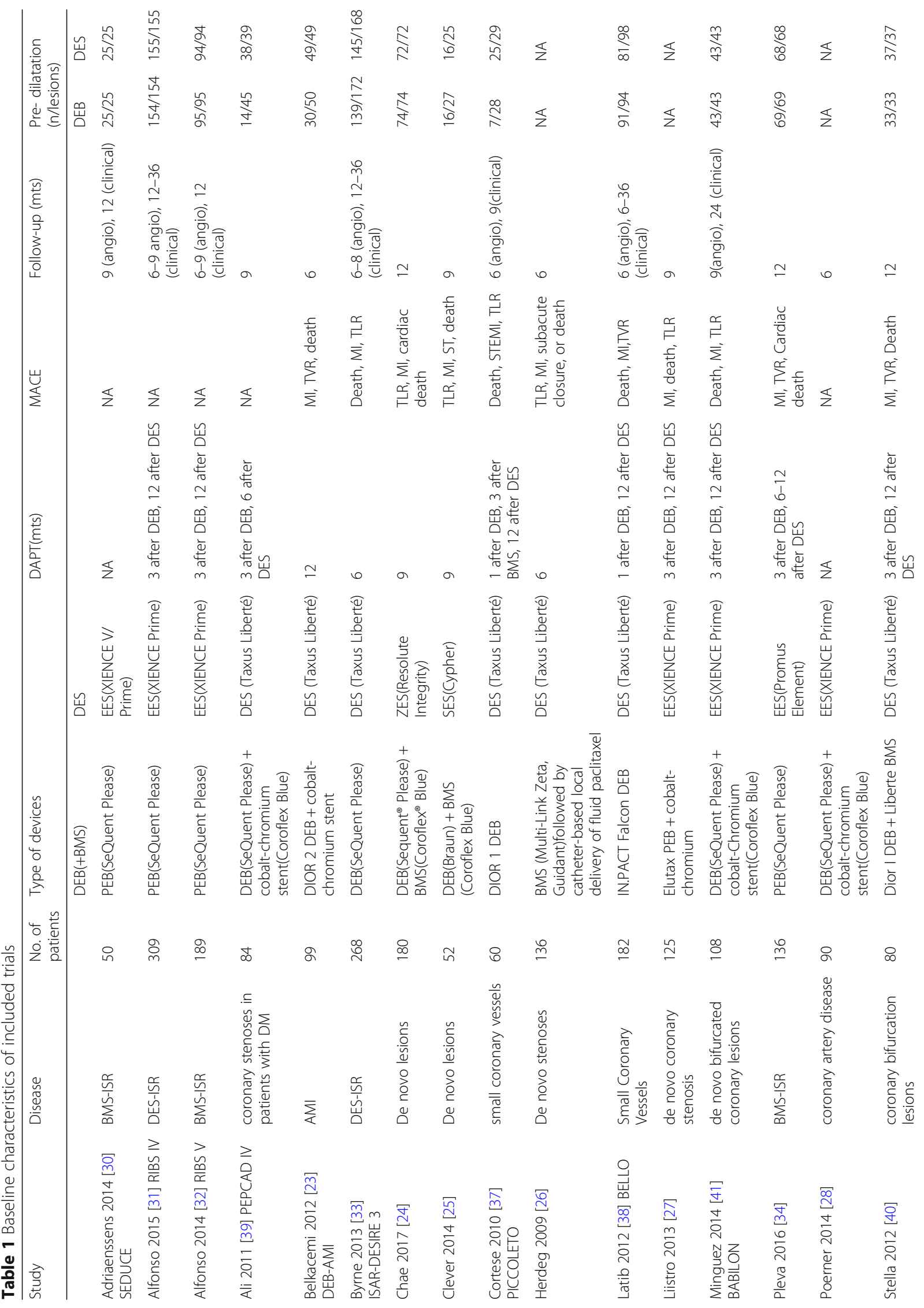




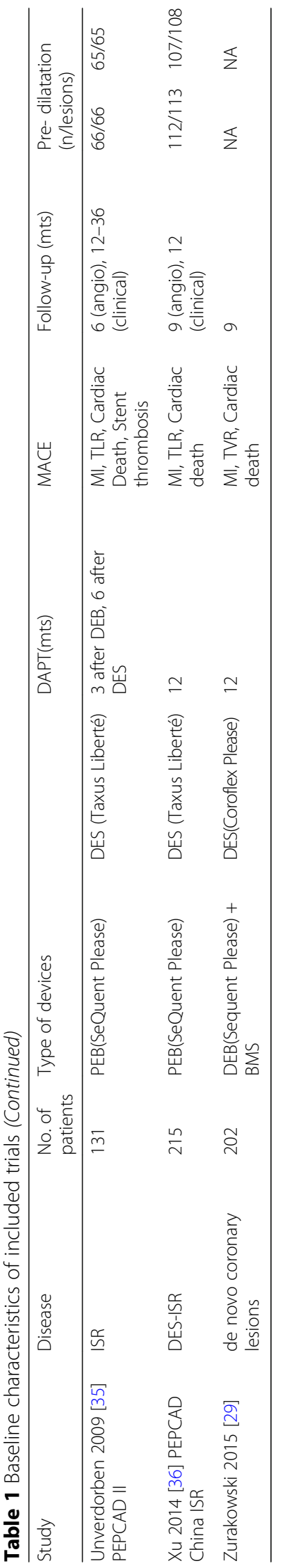




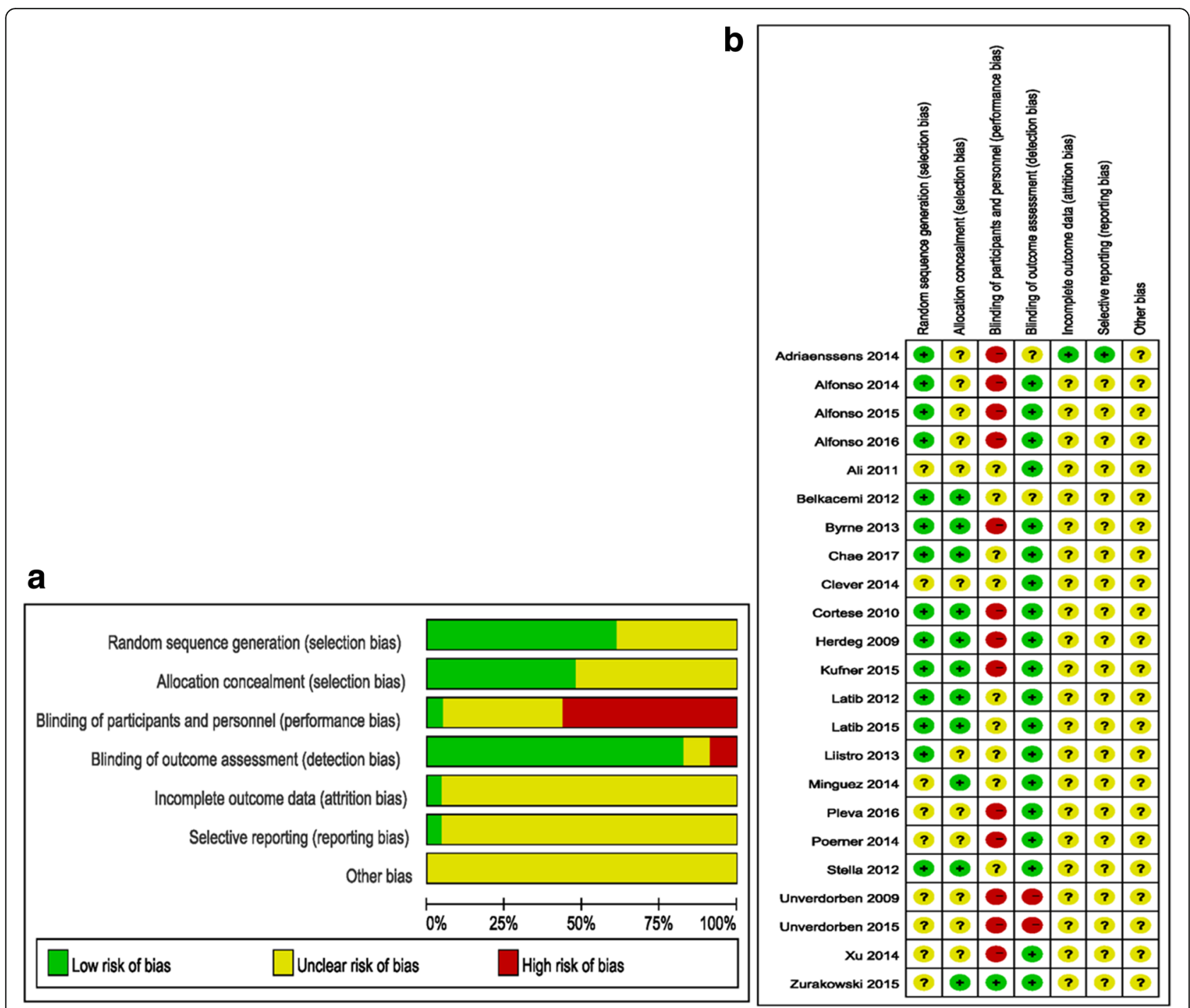

Fig. 2 Risk of Bias Assessment. a Risk of bias graph; b Risk of bias summary

$I^{2}=48 \%$ ). Comparable results were also shown in the DEB subgroup compared to the first-generation DES (RR $\left.1.05(0.74,1.47) ; P=0.80, \mathrm{I}^{2}=34 \%\right)$ and $\mathrm{DEB}$ versus the second-generation DES group (RR 1.47 (0.80, 2.72); $P=0.22, \mathrm{I}^{2}=61 \%$ ) (Fig. 3). Another subgroup analysis of $D E B$ versus DES in the treatment of de novo coronary diseases also showed no favorable MACE profile in the DES group (RR 1.35 (0.84, 2.16); $\mathrm{P}=0.22, \mathrm{I}^{2}=49 \%$ ). In addition, no difference in the ISR subgroup (RR 1.05 $\left.(0.68,1.63) ; P=0.82, \mathrm{I}^{2}=54 \%\right)$ was observed between the DEB and DES groups (Fig. 4).

\section{Secondary endpoints}

\section{LLL (in-lesion)}

Compared to the DES group, the DEB group had a significantly larger LLL (MD $0.11(0.01,0.22) ; P=0.03, \mathrm{I}^{2}=$ 85\%) (Fig. 5). However, there was no difference between the DEB group and the first-generation DES group (MD 0.09 ( $\left.-0.06,0.25) ; P=0.23, \mathrm{I}^{2}=85 \%\right)$. In addition, a subgroup analysis of DEB versus DES in de novo coronary diseases showed significant superiority of DES in LLL reduction, with high statistical heterogeneity across trials (MD $\left.0.21(0.07,0.35) ; P=0.004, \mathrm{I}^{2}=86 \%\right)$. Nevertheless, DEB presented similar efficacy in terms of ISR subgroup compared to the DES group (MD -0.03 $(-0.17,0.11) ; P$ $=0.67, \mathrm{I}^{2}=77 \%$ ) (Fig. 6).

$\mathrm{Br}$

The difference between the DEB and DES groups was statistically significant with regards to the incidence of BR (RR $\left.1.46(1.00,2.13) ; P=0.05, \mathrm{I}^{2}=53 \%\right)$. The secondgeneration DES group was significantly different compared to the DEB group (RR $2.16(1.02,4.54) ; P=0.04$, $\left.\mathrm{I}^{2}=58 \%\right)$. However, in the first-generation DES group, 


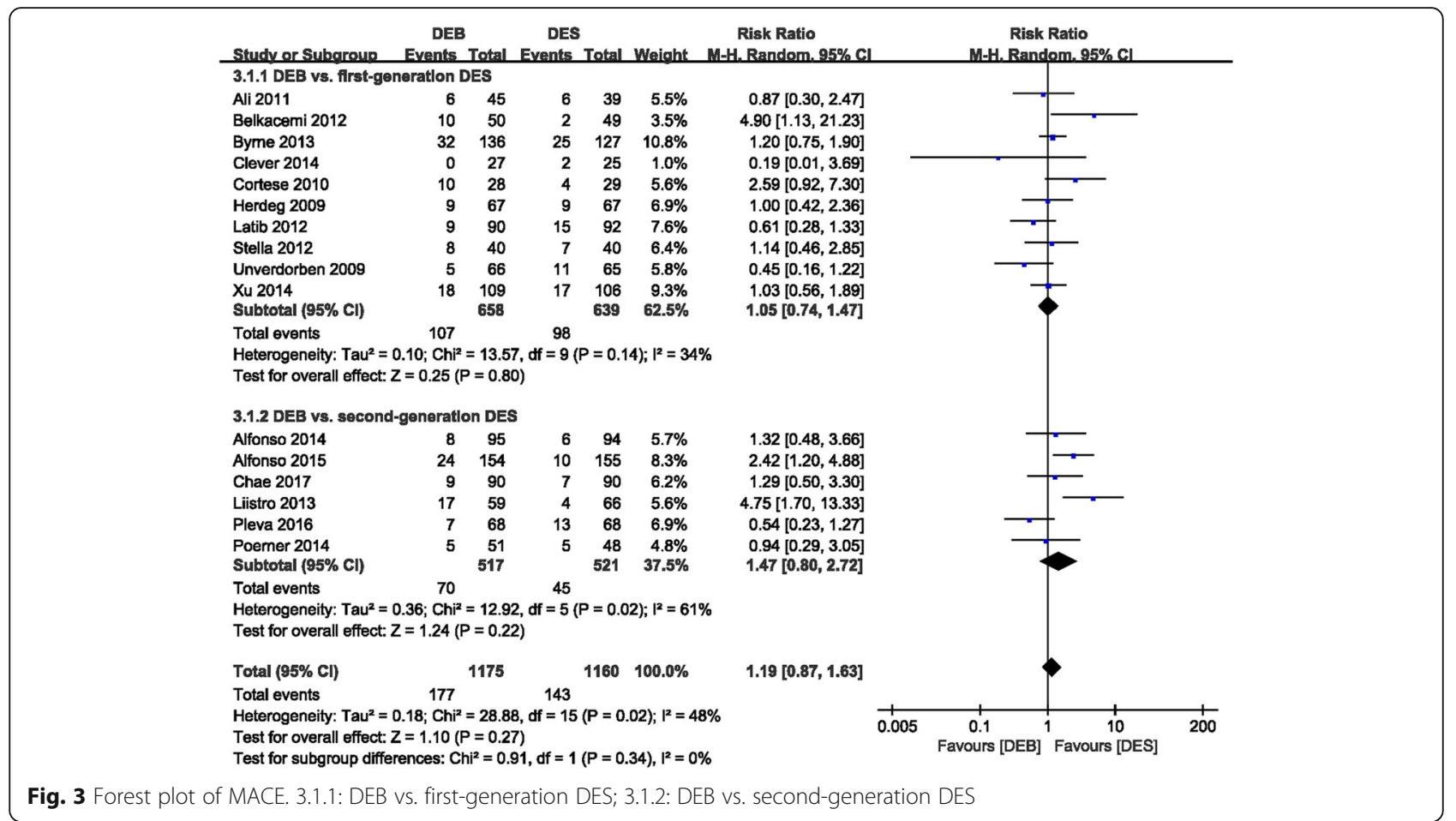

the incidence of BR was similar to that of the DEB group (RR 1.17 (0.77, 1.77); $P=0.46, \mathrm{I}^{2}=42 \%$ ) (Fig. 7).

\section{TLR}

There was no significant difference in TLR between the DEB and DES groups, with moderate statistical heterogeneity (RR $\left.1.32(0.88,1.99) ; P=0.18, \mathrm{I}^{2}=51 \%\right)$. The TLR occurrence rate in the first-generation DES group (RR $\left.1.17(0.74,1.83) ; P=0.50, \mathrm{I}^{2}=43 \%\right)$ and second-generation DES group (RR 1.65 (0.70, 3.90); $P$ $=0.25, \mathrm{I}^{2}=62 \%$ ) were both comparable to that of the DEB group (Fig. 8).

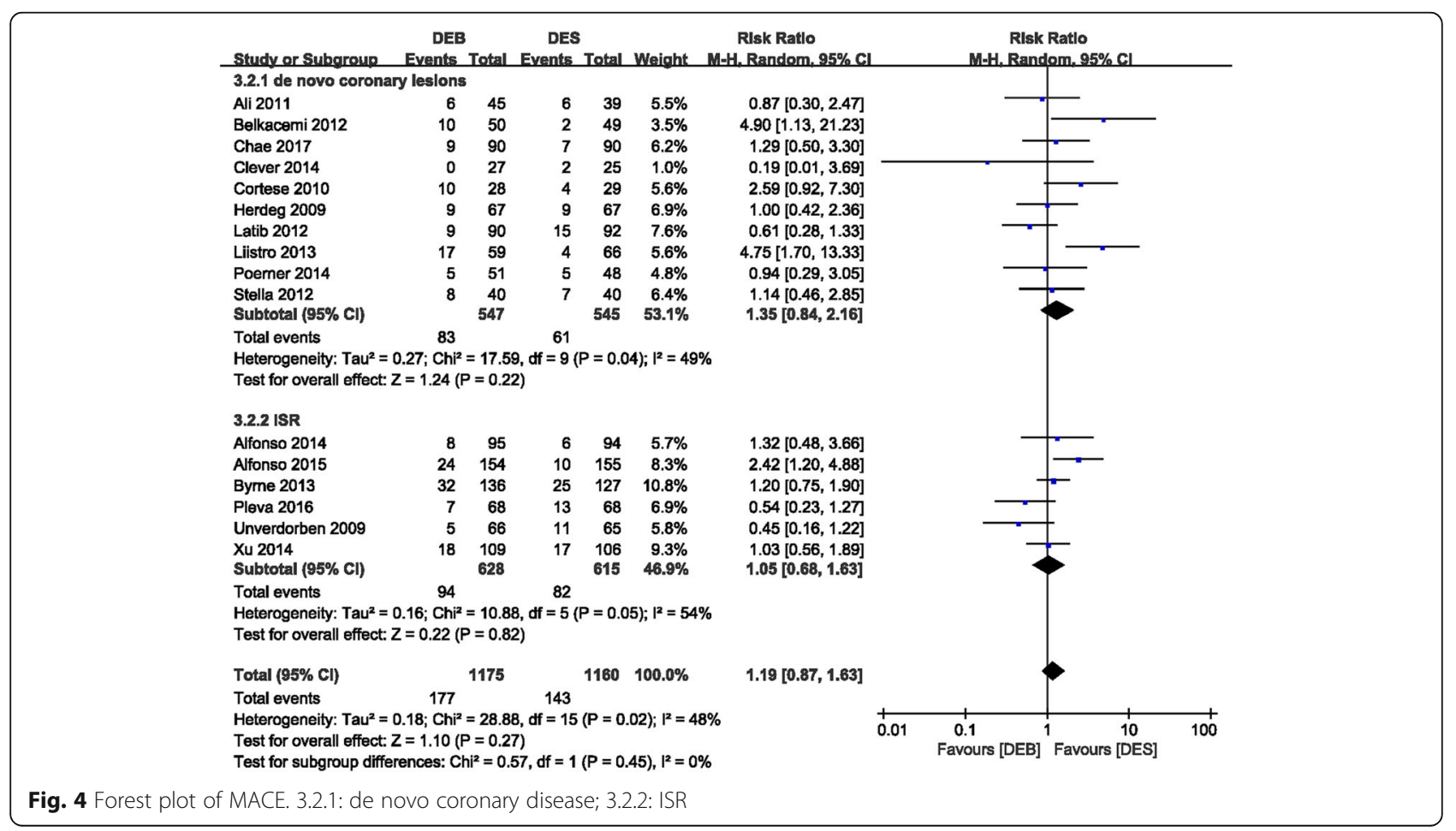




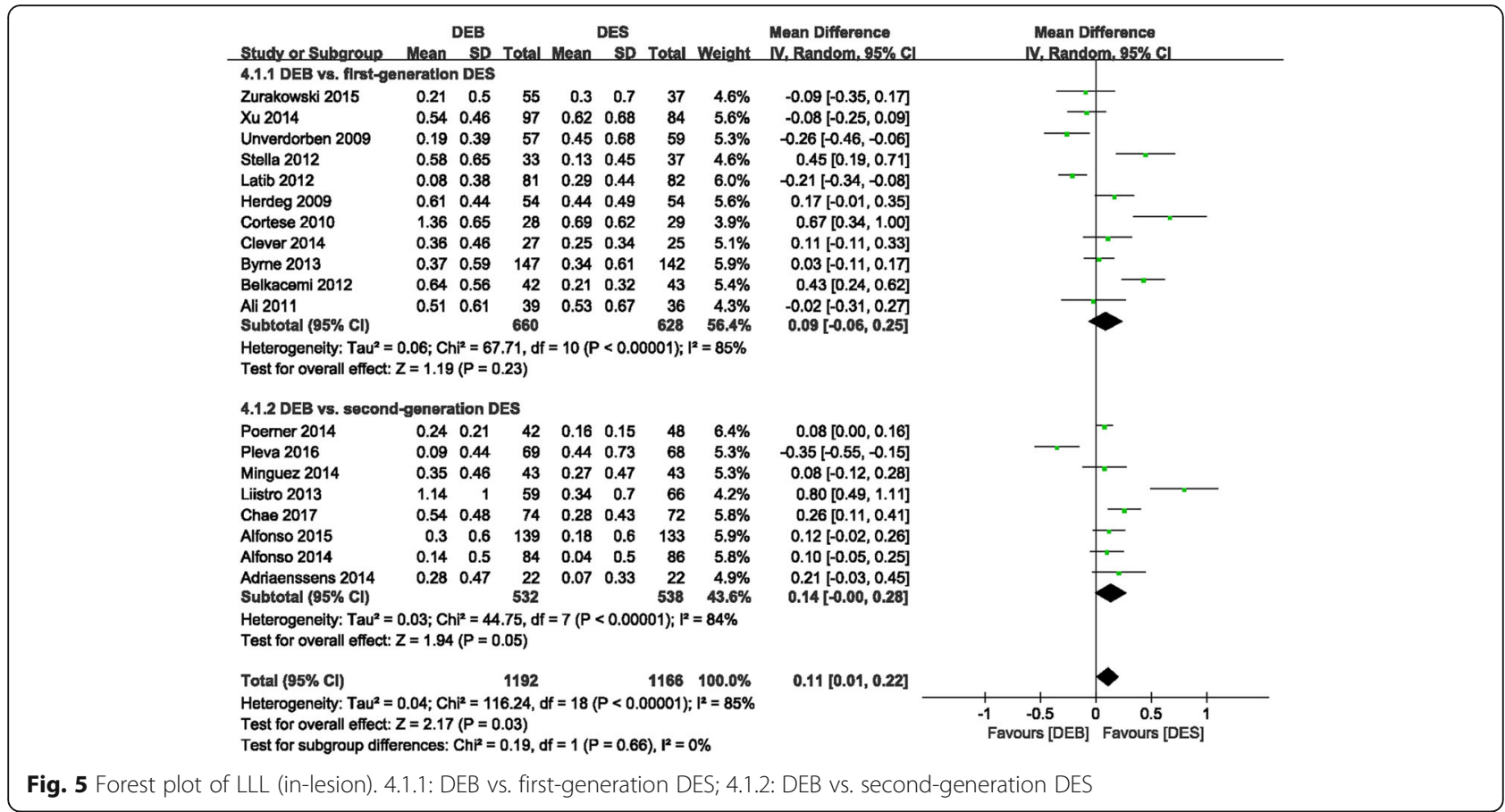

MI

Overall, the risk for MI was not significantly different between the DEB group and the control group, with no statistical heterogeneity (RR $0.83(0.50,1.38) ; P=0.48, \mathrm{I}^{2}$ $=0 \%$, as was also true in the subgroup analysis of the first-generation DES group (RR $0.66(0.34,1.27) ; P=$ $0.21, \mathrm{I}^{2}=0 \%$ ) and the second-generation DES group (RR $\left.1.21(0.53,2.72) ; P=0.65, \mathrm{I}^{2}=0 \%\right)$ when compared to the DEB group (Fig. 9).

\section{Mortality}

The mortality rate was not significantly different between the DEB and control groups (RR $1.01(0.58,1.79)$; $\left.P=0.96 ; \mathrm{I}^{2}=0 \%\right)$. Comparable results were also obtained

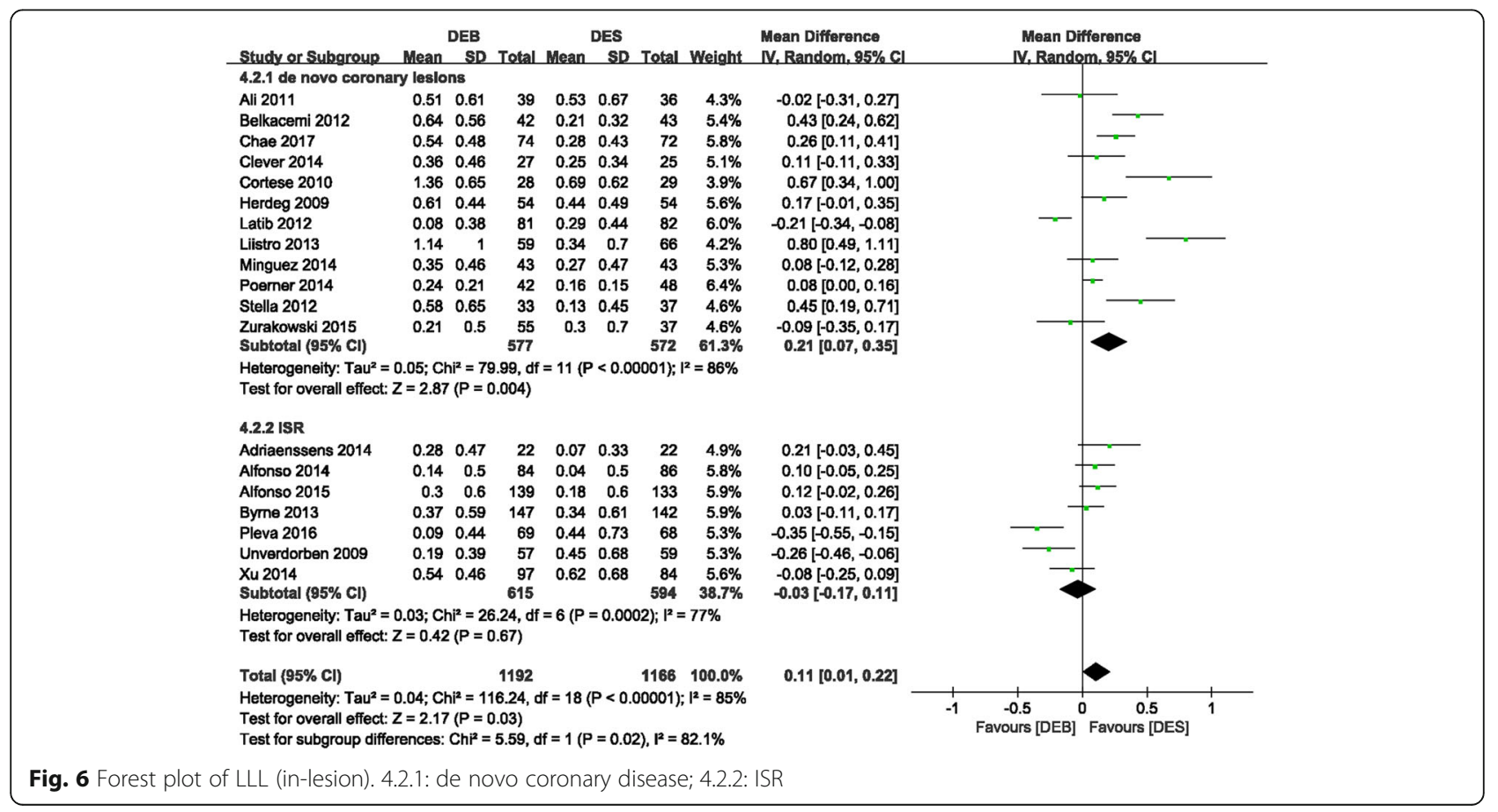




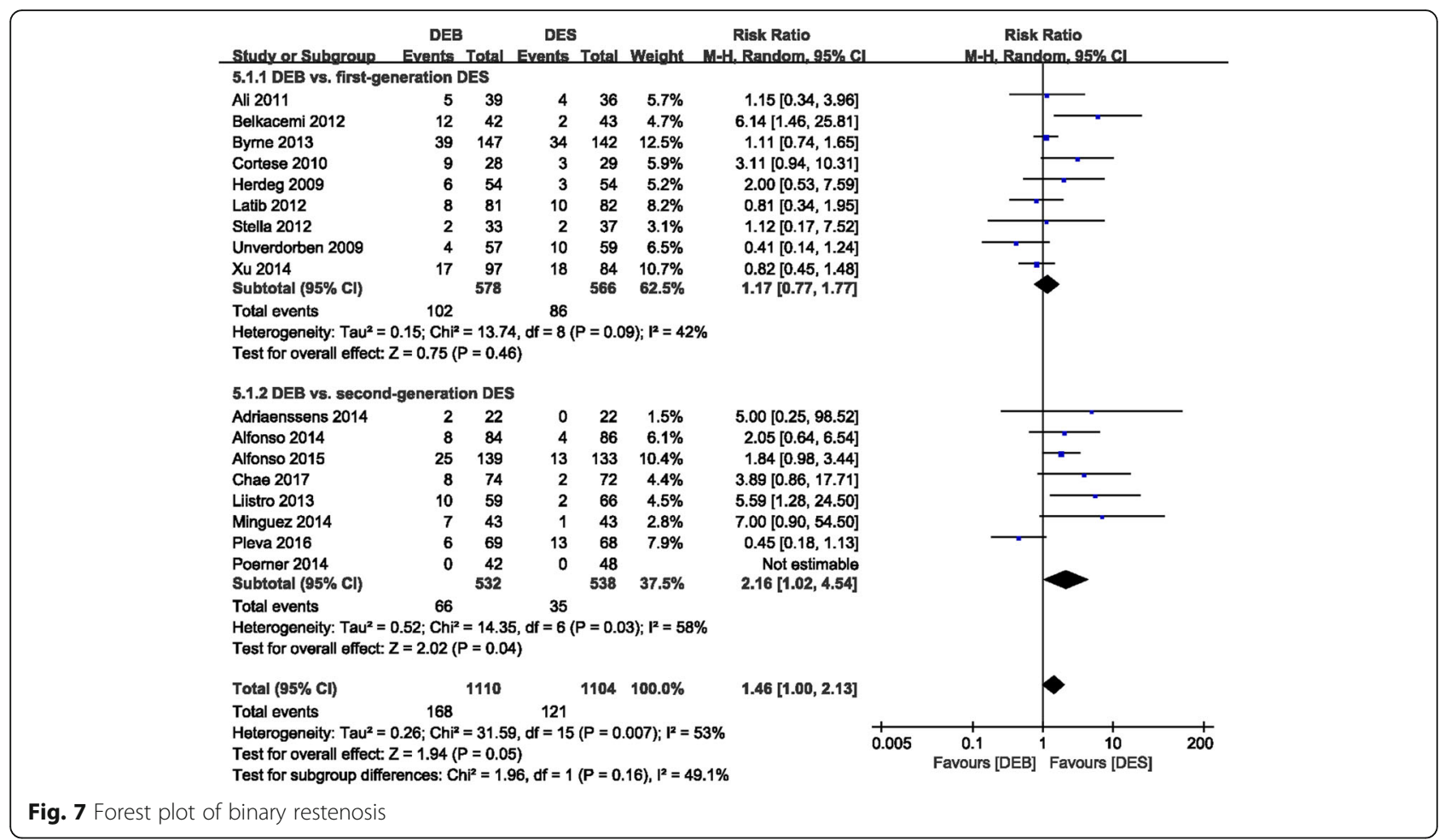

\begin{tabular}{|c|c|c|c|c|c|c|c|c|c|c|c|}
\hline & Study or Subgroup & $\begin{array}{r}\text { DEE } \\
\text { Events }\end{array}$ & 3 Total & $\begin{array}{c}\text { DES } \\
\text { Events }\end{array}$ & Tofal & Weight M-H, & $\begin{array}{l}\text { Risk Ratio } \\
\text {-H, Random, } 95 \% \text { Cl }\end{array}$ & & $\begin{array}{r}\text { Risk I } \\
\text { M-H, Rand }\end{array}$ & $\begin{array}{l}\text { Ratio } \\
\text { lom, } 95 \% \mathrm{Cl}\end{array}$ & \\
\hline & 6.1.1 DEB vs, first-ge & neration & DES & & & & & & & & \\
\hline & All 2011 & 3 & 45 & 4 & 39 & $5.1 \%$ & $0.65[0.15,2.73]$ & & & E & \\
\hline & Belkacemi 2012 & 10 & 50 & 1 & 49 & $3.1 \%$ & $9.80[1.30,73.69]$ & & & & \\
\hline & Byme 2013 & 30 & 136 & 17 & 127 & $10.8 \%$ & $1.65[0.96,2.84]$ & & & - & \\
\hline & Clever 2014 & 0 & 27 & 2 & 25 & $1.6 \%$ & $0.19[0.01,3.69]$ & & & & \\
\hline & Cortese 2010 & 9 & 28 & 3 & 29 & $6.2 \%$ & $3.11[0.94,10.31]$ & & & & \\
\hline & Herdeg 2009 & 9 & 67 & 8 & 67 & $8.2 \%$ & $1.13[0.46,2.74]$ & & 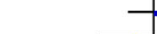 & $\leftarrow$ & \\
\hline & Latib 2012 & 4 & 90 & 7 & 92 & $6.2 \%$ & $0.58[0.18,1.93]$ & & & & \\
\hline & Stella 2012 & 6 & 40 & 6 & 40 & $7.1 \%$ & $1.00[0.35,2.84]$ & & & & \\
\hline & Unverdorben 2009 & 4 & 66 & 10 & 65 & $6.7 \%$ & $0.39[0.13,1.19]$ & & & & \\
\hline & $\begin{array}{l}\text { Xu } 2014 \\
\text { Subtotal } 195 \% \text { cl }\end{array}$ & 16 & $\begin{array}{l}109 \\
658\end{array}$ & 11 & $\begin{array}{l}106 \\
639\end{array}$ & $\begin{array}{r}9.4 \% \\
64.6 \%\end{array}$ & $1.41[0.69,2.90]$ & & & & \\
\hline & $\begin{array}{l}\text { Subtotal (95\% Cl) } \\
\text { Total events }\end{array}$ & 91 & & 69 & & $64.6 \%$ & $1.17[0.74,1.83]$ & & & & \\
\hline & $\begin{array}{l}\text { Heterogeneity: } \text { Tau }^{2}= \\
\text { Test for overall effect: }\end{array}$ & $\begin{array}{l}0.20 ; \mathrm{Chi}^{2} \\
\mathrm{z}=0.67(\end{array}$ & $\begin{array}{l}2=15.67 \\
P=0.50\end{array}$ & , df $=9$ (P & $P=0.07$ & $77) ; 1^{2}=43 \%$ & & & & & \\
\hline & 6.1.2 DEB vs, second & -generati & ion DES & & & & & & & & \\
\hline & Adriaenssens 2014 & 1 & 24 & 2 & 25 & $2.5 \%$ & $0.52[0.05,5.38]$ & & & & \\
\hline & Alfonso 2014 & 6 & 95 & 1 & 94 & $3.0 \%$ & $5.94[0.73,48.37]$ & & & & \\
\hline & Alfonso 2015 & 20 & 154 & 7 & 155 & $8.6 \%$ & $2.88[1.25,6.60]$ & & & $\longrightarrow$ & \\
\hline & Chae 2017 & 5 & 90 & 3 & 90 & $5.2 \%$ & $1.67[0.41,6.77]$ & & & 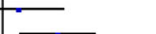 & \\
\hline & Liistro 2013 & 15 & 59 & 3 & 66 & $6.3 \%$ & $5.59[1.70,18.36]$ & & & & \\
\hline & Pleva 2016 & 5 & 68 & 11 & 68 & $7.4 \%$ & $0.45[0.17,1.24]$ & & & & \\
\hline & Poerner 2014 & 1 & 51 & 2 & 48 & $2.4 \%$ & $0.47[0.04,5.02]$ & & & & \\
\hline & Subtotal $(95 \% \mathrm{Cl}$ ) & & 541 & & 546 & $35.4 \%$ & $1.65[0.70,3.90]$ & & & & \\
\hline & $\begin{array}{l}\text { Total events } \\
\text { Heterogeneity: Tau² }= \\
\text { Test for overall effect: }\end{array}$ & $\begin{array}{r}53 \\
0.75 ; \mathrm{Chi}^{2} \\
\mathrm{z}=1.14(\end{array}$ & $\begin{array}{l}2=15.59 \\
P=0.25\end{array}$ & , df $=6(\mathrm{~F}$ & $P=0.02$ & $2) ; 1^{2}=62 \%$ & & & & & \\
\hline & Total $(95 \% \mathrm{Cl})$ & & 1199 & & 1185 & $100.0 \%$ & $1.32[0.88,1.99]$ & & & 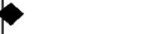 & \\
\hline & Total events & 144 & & 98 & & & & & & & \\
\hline & $\begin{array}{l}\text { Heterogeneity: } \text { Tau }^{2}= \\
\text { Test for overall effect: } \\
\text { Test for subgroup diffe }\end{array}$ & $\begin{array}{l}0.33 ; \text { Chi" }^{2} \\
z=1.33( \\
\text { rences: } \mathrm{C}\end{array}$ & 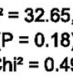 & $\begin{array}{l}\mathrm{df}=16 \\
\mathrm{l}, \mathrm{df}=1\end{array}$ & $\begin{array}{l}(P=0.0 \\
(P=0.4\end{array}$ & $\begin{array}{l}.008) ; 1^{2}=51 \% \\
.48), l^{2}=0 \%\end{array}$ & & 0.002 & Favours [DEB] $^{0.1}$ & ${ }^{i} \frac{10}{10}$ Favours [DES] & 500 \\
\hline Fig. 8 Forest plot o & fTLR & & & & & & & & & & \\
\hline
\end{tabular}




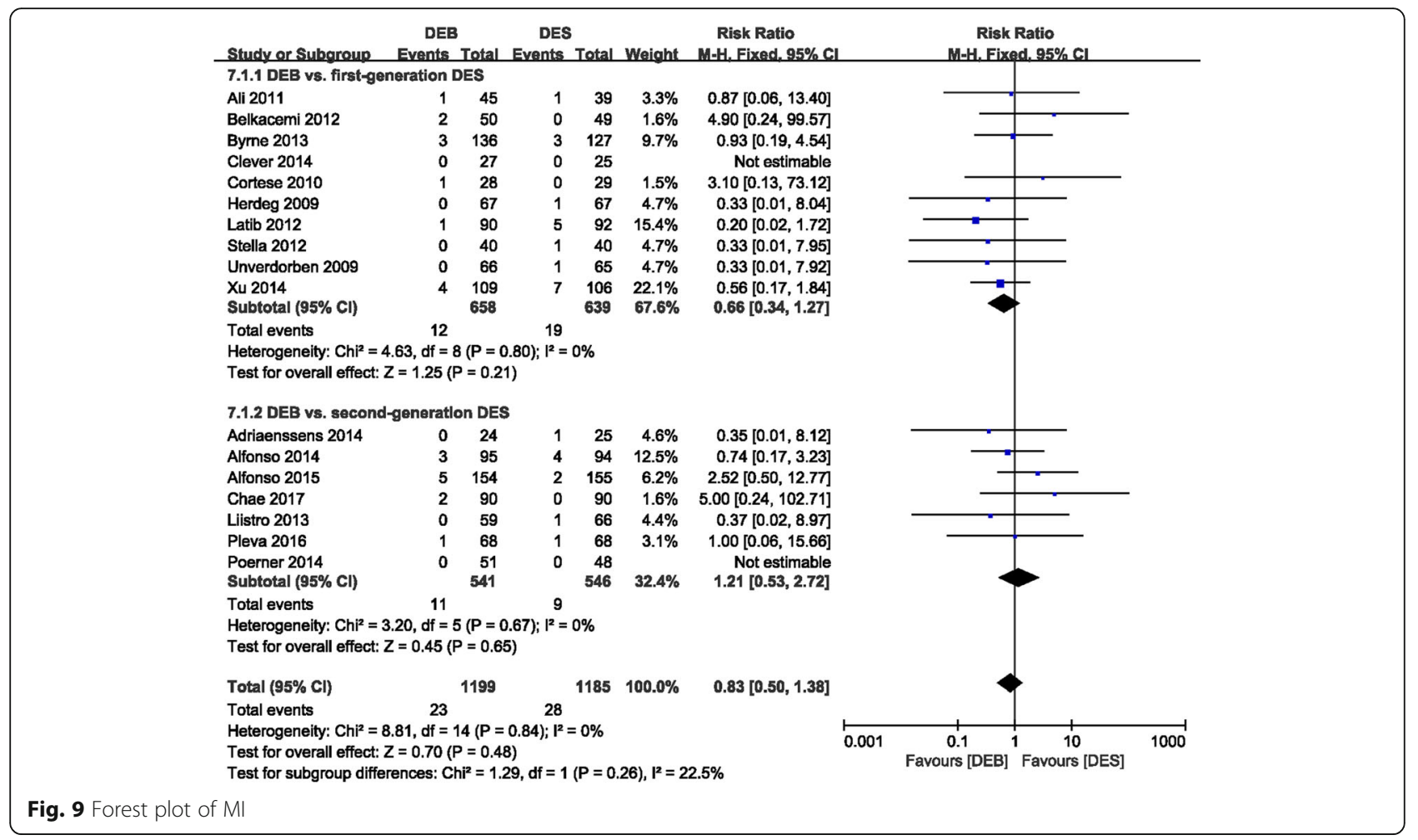

in the subgroup analysis of the first-generation DES group $\left(0.75(0.34,1.64) ; P=0.47, \mathrm{I}^{2}=0 \%\right)$ and the second-generation DES group (RR 1.44 (0.62, 3.35); $P=$ $0.40, \mathrm{I}^{2}=0 \%$ ) compared to the DEB group, respectively (Fig. 10).

\section{Long-term follow-up}

PEPCAD II, BELLO, ISAR-DESIRE 3, and RIBS V were published in the third year of follow-up, while Minguez' study [41] was published in the second year of clinical follow-up. Thus, we extracted and conducted the analysis of the meaningful data such as MACE, TLR, MI, and mortality of these studies, and the results showed that the long-term safety was comparable between the DEB and DES groups: MACE (RR $0.91(0.62,1.34) ; P=$ $\left.0.64, \mathrm{I}^{2}=56 \%\right) ;$ MI (RR $1.15(0.54,2.46) ; P=0.71, \mathrm{I}^{2}=$ $0 \%)$; mortality (RR $\left.0.78(0.31,1.98) ; P=0.61, \mathrm{I}^{2}=56 \%\right)$; and TLR (RR $1.26(0.59,2.68) ; \quad P=0.55, \mathrm{I}^{2}=65 \%$ ) (Fig. 11).

\section{Sensitivity analysis}

After eliminating the included trials one by one, the results did not significantly change when the effect size of each endpoint was pooled together.

\section{Publication bias test}

The Egger test showed no evidence of significant publication bias in the present meta-analysis, according to LLL (in-lesion) $(P=0.122)$ and MACE $(P=0.991)$. The funnel plots of the primary endpoints were symmetrical, further suggesting that there was no publication bias in this meta-analysis (Fig. 12).

\section{Discussion}

A major goal of this meta-analysis was to evaluate the safety and efficacy of DEB (+/-BMS) for treatment of all types of CAD. The main findings of this meta-analysis are summarized as follows: 1) Overall, DEB demonstrated a similar safety profile in the primary outcome of reducing MACE risk and other clinical outcomes, including TLR, MI and mortality, compared to the DES group (regardless of first-generation or second-generation DES); 2) There was a favorable efficacy of reducing LLL and BR at 6 to 12 months angiographic follow-up shown in the DES group, especially in the second-generation DES subgroup; 3) DES was more efficacious in treating de novo coronary diseases, but DES exhibited equivalent efficacy in the treatment of ISR compared to DEB; 4) Analysis of longterm follow-up showed no significant difference between DEB and DES when considering MACE, MI, mortality, and TLR. The present study suggests that DEB may be as efficacious and safe as the first-generation DES, and DEB may also be beneficial with regards to safety concerns compared to the second-generation DES. However, larger trials are needed to confirm these findings.

Despite the significant advances in DES treatment of CAD, some complex vessel lesions such as SVD and bifurcation lesions, which account for 15\% - 18\% of CAD, 


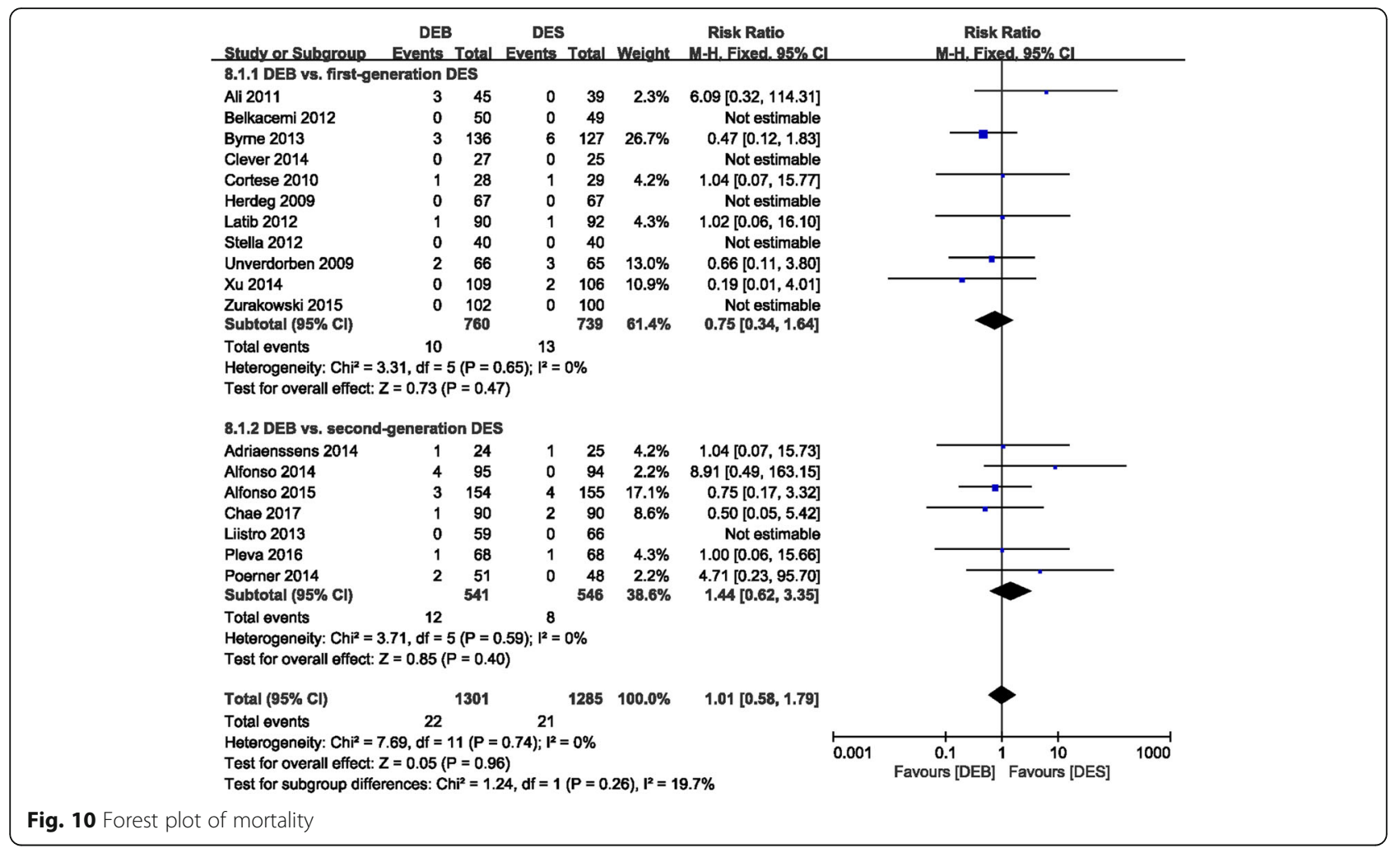

are usually accompanied by a high incidence of ISR and often lead to a high probability of revascularization. Many patients with CAD have diabetes, and the vessel lesions in these patients are usually widespread and extensive. In terms of ISR, DES adds an extra layer of struts that could narrow the lumen, and may complicate further development of ISR. However, the Treatment of InStent Restenosis by Paclitaxel-Coated Balloon Catheters (PACCOCATH ISR) study, which was the first to apply DEB in humans for ISR treatment [46], showed that DEB was significantly better at reducing ISR compared to the plain old balloon angioplasty (POBA), indicating that DEB could be effective at treating CAD. Due to its highly lipophilic property, paclitaxel is currently widely used in DEB for percutaneous coronary intervention (PCI) [14]. DEB can deliver higher paclitaxel doses (300 to $600 \mu \mathrm{g}$ ) compared to DES struts (100 to $200 \mu \mathrm{g}$ ), the latter of which commonly covers only $20 \%$ of the injured vessel wall. Therefore, a larger DEB surface area guarantees more uniform drug delivery to the vascular wall [47]. Recent studies suggested that DEB improved coronary blood supply and vascular function when used to treat severe CAD $[48,49]$. Moreover, $\mathrm{DEB}$ is more advantageous than DES in terms of homogenous drug application, extensive contact area, absence of stent strut, reducing inflammation and risk of thrombosis, and shortening endothelial healing time [50].
Previous studies have presented inconsistent conclusions regarding DEB compared to DES for coronary artery lesions [47, 51-53]. The present meta-analysis showed that the efficacy of DEB was inferior to DES. However, the diabetic coronary stenosis in Ali's study [39] and the de novo coronary stenosis in Zurakowski's study [29] were not statistically different with regards to clinical and angiographic outcomes after 9 months of treatment. Furthermore, Latib et al. [38] reported that that DEB was better than DES for treatment of SVD patients with diabetes, and that DEB generally obtained similar favorable therapeutic effects on small vessel lesions compared to DES. Sinaga et al. [48] also reported that DEB-only angioplasty delivered good clinical outcomes after 1 year of treatment, which were comparable with DES-treated SVD patients. In addition, Naganuma's study [54] retrospectively investigated the safety of DEB compared to the second-generation DES for treating ISR involving bifurcated lesions. This study also showed that DEB may be an acceptable treatment option with similar incidences of MACE in the two groups.

The lack of efficacy may originate from various factors. One possible reason accounting for DES's superiority over DEB may be that the pre-dilation with a conventional balloon was not sufficient in the DEB group and that only early-generation DEB was used. Theoretically, prior to the use of DEB, non-coated semi-conformable 


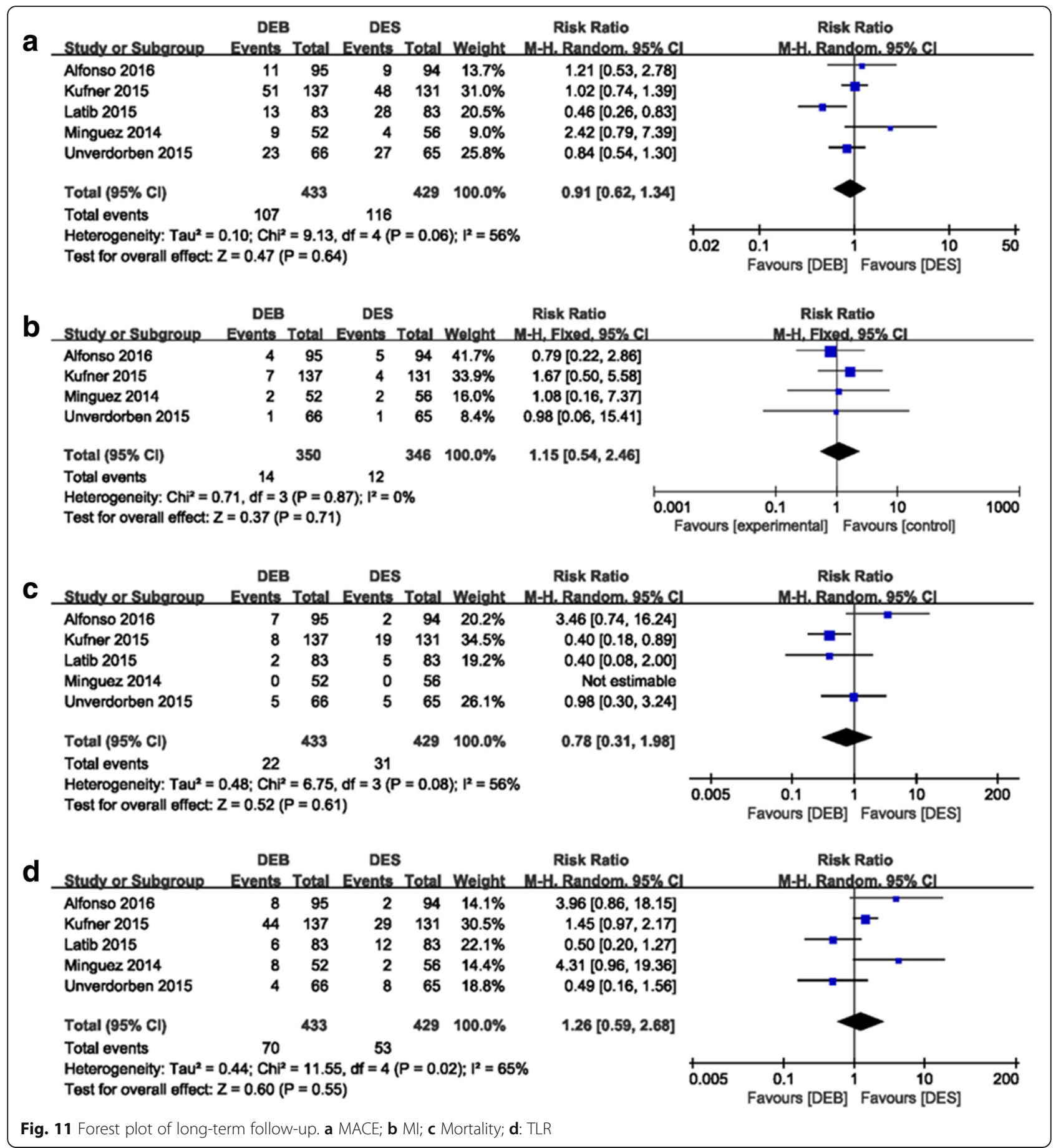

balloon (balloon to vascular ratio of 0.8-1.0, expansion pressure higher than normal) treatment of lesions could facilitate the transfer of drugs from the balloon to the vessel wall [33]. Current guidelines mandate that the stenosis should first be adequately dilated with a normal balloon angioplasty to ensure the deliverability of $\mathrm{DEB}$ to the site of the treated segment [39]. Although predilation with a conventional balloon catheter was commonly used prior to DES deployment, pre-dilation before the use of DEB differed among trials and was usually insufficient. It is not clear in our meta-analysis if this difference was due to the method of balloon deployment. More clinical trials with a large cohort are needed to further corroborate this observation.

Another possible explanation for the findings may be the technique and excipient used on the balloon, which failed to guarantee sufficient drug transfer to the vessel wall. A recent study compared various DEBs in a 


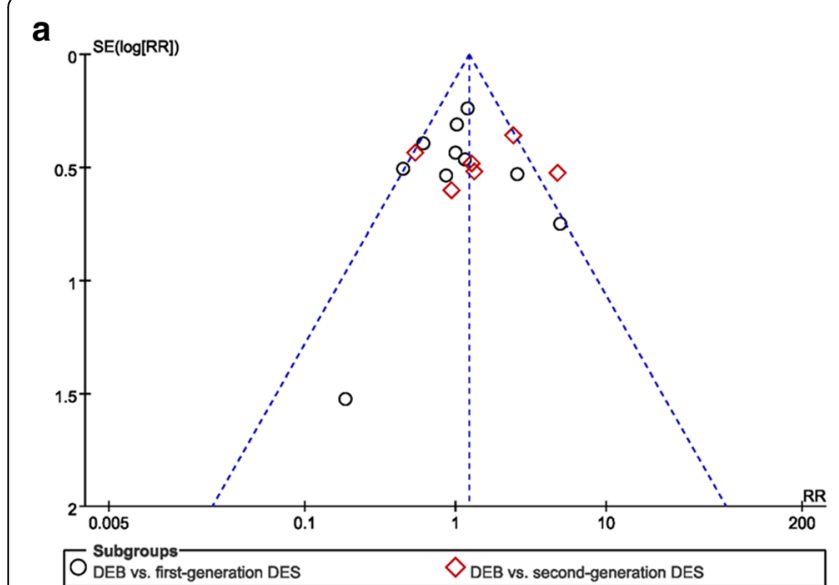

Fig. 12 Funnel plot of publication bias. A: MACE; B: LLL (in-lesion)

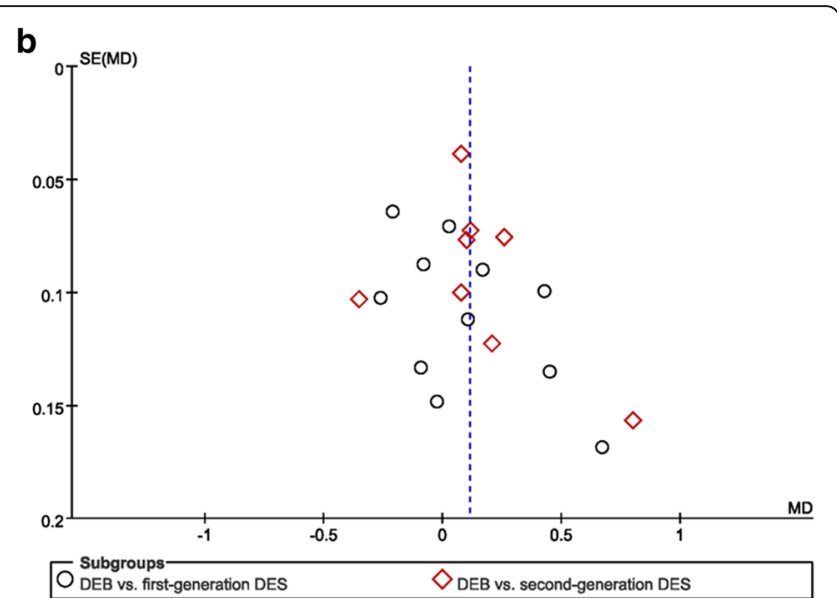

porcine model and showed that drug concentration in the vessel wall was much higher with the use of DIOR-II DEB than the DIOR-I, demonstrating that effective excipients are necessary to accomplish successful balloon facilitated paclitaxel delivery. The present study showed that DEB was as efficacious and safe as the first-generation DES, which led to an assumption that DEB may achieve better results because of improved techniques and excipients, such as employing new biocompatible polymer coatings.

Other justifications of the above findings include: 1) Paclitaxel released by DEB might not be able to supply powerful intimal response because of its single "shot" approach. However, it has been demonstrated that the amount of paclitaxel transferred to the vessel wall was still in a bio-effective range after 7 days following balloon inflation [55]; 2) The experimental group included DEB with BMS, which may lead to a geographical mismatch between the DEB-treated area and BMS implantation. However, stent length was always inferior to the segment treated with DEB, and we did not observe any evidence of geographical mismatch among these studies; 3) There may be higher neointimal hyperplasia in the DEB group. An IVUS substudy of the PEPCAD III [56] confirmed higher neointimal hyperplasia in the DEB + BMS group. However, a DEB-AMI study [23], which conducted OCT analysis, showed a reduction of neointimal hyperplasia in the DEB group. The present study showed no difference in the reduction of clinical events between DEB and DES, which may need to be further validated.

PEPCAD II [42], BELLO [43], ISAR-DESIRE 3 [44], and RIBS V [45] were published in the third year of follow-up, and Minguez's study reported data at 24 months clinical follow-up. Thus, the results of MACE, TLR, MI, and mortality extracted from the above studies were statistically analyzed. The DEB and DES groups were not significantly different in long-term safety. However, the population included in this meta-analysis was too small to draw a definitive conclusion regarding safety. Thus, there is an imperative need for longer and larger-scale clinical trials to evaluate long-term effects of DEB. The sample size and power of the current analysis were not adequate to evaluate rare outcomes such as death and ST.

Nevertheless, DEB still had the following advantages over DES: (1) avoiding overlap of the 2-layer or even 3layer stent and thus reducing the negative effects on coronary anatomy; (2) evenly transporting the drug to the vascular wall, subsequently diminishing delayed endothelialization caused by the heterogeneous distribution of the stent strut; (3) having no polymer, thus not inducing late thrombosis; and (4) reducing the duration of DAPT. Therefore, in clinical practice, DEB is an alternative option for treatment of some CAD, such as SVD, anatomical curved vessels, diffuse long lesions, and bifurcation lesions, when DES is not appropriate. Thus, we believe that, if used properly with the correct operation procedures, DEB could be an optimal choice for CAD treatment, especially for patients who require shorter double antiplatelet therapy or have bleeding tendencies. Still, a considerable number of studies are needed to provide solid evidence to support the replacement of DES by DEB in treatment of SVD and other difficult CADs.

\section{Limitations}

Trials that were included in this study compared DEB with DES in a variety of patients with different types of $\mathrm{CAD}$; the high degree of statistical heterogeneity raised the question of suitability in pooling these trial data, and thus our results in the overall CAD group should be 
interpreted with caution. Also, the types of DEB or DES used in the included trials were inconsistent, which may be a cause of heterogeneity. However, when we carried out sensitivity analysis, the combined effect of the amount showed no significant changes.

\section{Outlook}

First-generation DES was reported in a majority of the trials included in this meta-analysis. However, the newgeneration DES, with thin strut stent platforms, increased biocompatibility and durability, or biodegradable polymers and limus-based antiproliferative agents, has higher efficacy and safety compared to old versions of DES, as evidenced by $10-20 \%$ reduction in repeat revascularization $[57,58]$. Thus, application of new-generation DES in treatment of CAD may obtain better clinical outcomes. Meanwhile, due to good experience of these drugs used in DES technology, the development of limus-based DEB catheters is of great interest. For instance, zotarolimus and sirolimus DEBs have been developed and tested in pigs with peripheral artery diseases, although they have not been investigated in humans $[25,59]$. Cremers and colleagues reported encouraging data with a novel zotarolimus-coated balloon [60]. In order to overcome problems caused by the long-term presence of stents in the blood vessels, biodegradable biological stents (bioresorbable scaffold, BRS) were designed. However, the thicker platform of these DES stents, ease of breaking, and increased tendency for the coated polymer to cause endothelium inflammatory proliferation have limited the application of BRS [61]. The CENTURY II trial [62] compared the effects of BRS and EES on SVD, and suggested that BRS had effects comparable to those of DES within a 12 month follow-up period. As a result, BRS, which will likely be thinner with future development and have a stronger brace and a faster degradation process, may offer better clinical outcomes. However, the current evidence does not support BRS; available evidence showed increased risk of TLR, MACE, and ST with BRS [63].

\section{Conclusions}

From this meta-analysis, we conclude that DEB is comparable to DES in terms of clinical outcomes, and even offered a comparable or even better outcome compared to DES after a 3-year follow-up period, suggesting that DEB is at least as safe as DES. However, larger RCTs are required to assess hard clinical outcomes, such as death, MI or ST, with adequate power.

\section{Additional file}

Additional file 1: Search strategy: Details of search strategy. (DOCX $24 \mathrm{~kb}$ ) Additional file 2: Baseline clinical data: Baseline clinical data of patients in the included studies. (DOCX $23 \mathrm{~kb}$ )

\section{Abbreviations}

95\% Cl: 95\% confidence interval; BR: Binary restenosis; CAD: Coronary artery disease; DAPT: Dual anti platelet therapy; DEB: Drug-eluting balloon; DES: Drug-eluting stent; ISR: In-stent restenosis; LLL: in-lesion late lumen loss; MACE: Major adverse cardiac events; MD: Mean Difference; MI: Myocardial infarction; PCI: Percutaneous coronary intervention; POBA: Plain old balloon angioplasty; QCA: Quantitative coronary angiography; RCT: Randomized controlled trial; RR: Risk ratio; ST: Stent thrombosis; SVD: Small vessel disease; TLR: Target lesion revascularization

\section{Acknowledgements}

None.

\section{Funding}

This work was supported by the Jilin Province Science and Technology Department (Program \#20170204032YY) and the Development and Reform Commission of Jilin Province (2017C049-1).

The major support was expert consultant, data analysis and language editing service.

Availability of data and materials

All data and materials used in this research are freely available. References have been provided.

\section{Authors' contributions}

WJN and LB conceived and designed the research. RJJ and HG searched and extracted the data. LLL and QC analyzed the results. LLL wrote the manuscript. All authors discussed the results and commented on the manuscript. All authors read and approved the final manuscript.

Ethics approval and consent to participate

Not applicable.

\section{Consent for publication}

Not applicable.

\section{Competing interests}

The authors declare that they have no competing interest.

\section{Publisher's Note}

Springer Nature remains neutral with regard to jurisdictional claims in published maps and institutional affiliations.

Received: 11 July 2017 Accepted: 7 February 2018

Published online: 02 March 2018

\section{References}

1. Erbel R, Wijns W. The year in cardiology 2013: coronary intervention. Eur Heart J. 2014;35(5):313-320.

2. Dehmer GJ, Weaver D, Roe MT, Milford-Beland S, Fitzgerald S, Hermann A, Messenger J, Moussa I, Garratt K, Rumsfeld J, et al. A contemporary view of diagnostic cardiac catheterization and percutaneous coronary intervention in the United States: a report from the CathPCI registry of the National Cardiovascular Data Registry, 2010 through June 2011. J Am Coll Cardiol. 2012;60(20):2017-31.

3. Katz G, Harchandani B, Shah B. Drug-eluting stents: the past, present, and future. Curr Atheroscler Rep. 2015;17(3):485.

4. Thomas MP, Bates ER. Update on primary PCI for patients with STEMI. Trends in Cardiovascular Medicine. 2017;27(2):95-102.

5. Theodoropoulos K, Mennuni MG, Dangas GD, Meelu OA, Bansilal S, Baber U, Sartori S, Kovacic JC, Moreno PR, Sharma SK, et al. Resistant in-stent restenosis in the drug eluting stent era. Catheter Cardiovasc Interv. 2016;88(5):777-85.

6. Unverdorben M, Kleber FX, Heuer H, Figulla H-R, Vallbracht C, Leschke M, Cremers B, Hardt S, Buerke M, Ackermann H, et al. Treatment of small coronary arteries with a paclitaxel-coated balloon catheter. Clin Res Cardiol. 2010;99(3):165-74

7. Lee JM, Park KW, Koo B-K, Kim H-S. Stenting of coronary bifurcation lesions: a literature and technical review. Current Cardiology Reports. 2015;17(6):45.

8. Wang H, Gao Z, Song Y, Tang X, Xu J, Jiang P, Jiang L, Chen J, Gao L, Song L, et al. Impact of diabetes mellitus on percutaneous coronary intervention in Chinese patients: a large single-center data. Angiology. 2017;3319717735226 
9. Armstrong EJ, Waltenberger J, Rogers JH. Percutaneous coronary intervention in patients with diabetes: current concepts and future directions. J Diabetes Sci Technol. 2014;8(3):581-9.

10. Loh JP, Barbash IM, Waksman R. The current status of drug-coated balloons in percutaneous coronary and peripheral interventions. Eurolntervention. 2013;9(8):979-88.

11. Gao L, Chen YD. Application of drug-coated balloon in coronary artery intervention: challenges and opportunities. J Geriatr Cardiol. 2016;13(11):906-13.

12. Byrne RA, Joner M, Alfonso F, Kastrati A. Drug-coated balloon therapy in coronary and peripheral artery disease. Nat Rev Cardiol. 2014;11(1):13-23.

13. Pósa A, Nyolczas N, Hemetsberger R, Pavo N, Petnehazy Ö, Petrasi Z, Sangiorgi G, Gyöngyösi M. Optimization of drug-eluting balloon use for safety and efficacy: evaluation of the 2nd generation paclitaxel-eluting DIOR-balloon in porcine coronary arteries. Catheter Cardiovasc Interv. 2010;76(3):395-403.

14. Richelsen RKB, Overvad TF, Jensen SE. Drug-eluting balloons in the treatment of coronary de novo lesions: a comprehensive review. Cardiology and Therapy. 2016;5(2):133-60

15. Moher D, Liberati A, Tetzlaff J, Altman DG. Preferred reporting items for systematic reviews and meta-analyses: the PRISMA statement. PLoS Med. 2009;6(7):e1000097.

16. Alfonso F, Garcia-Guimaraes M. Optimal coronary interventions in small vessels: is size all that matters? JACC Cardiovascular interventions. 2016;9(13):1335-7.

17. Kleber FX, Rittger H, Ludwig J, Schulz A, Mathey DG, Boxberger M, Degenhardt R, Scheller B, Strasser RH. Drug eluting balloons as stand alone procedure for coronary bifurcational lesions: results of the randomized multicenter PEPCAD-BIF trial. Clin Res Cardiol. 2016;105(7):613-21.

18. Higgins JPT, Green S (editors). Cochrane Handbook for Systematic Reviews of Interventions Version 5.1.0 [updated March 2011]. The Cochrane Collaboration, 2011. Available from http://handbook.cochrane.org.

19. Riley RD, Higgins JP, Deeks JJ. Interpretation of random effects meta-analyses BMJ. 2011;342:d549.

20. Higgins JPT, Thompson SG. Quantifying heterogeneity in a meta-analysis. Stat Med. 2002;21(11):1539-58.

21. Bowden J, Tierney JF, Copas AJ, Burdett S. Quantifying, displaying and accounting for heterogeneity in the meta-analysis of RCTs using standard and generalised Qstatistics. BMC Med Res Methodol. 2011;11(1):41.

22. Juni $P$, Witschi $A$, Bloch $R$, Egger $M$. The hazards of scoring the quality of clinical trials for meta-analysis. JAMA. 1999;282(11):1054-60.

23. Belkacemi A, Agostoni P, Nathoe HM, Voskuil M, Shao C, Van Belle E, Wildbergh T, Politi L, Doevendans PA, Sangiorgi GM, et al. First results of the DEB-AMI (drug eluting balloon in acute ST-segment elevation myocardial infarction) trial: a multicenter randomized comparison of drug-eluting balloon plus bare-metal stent versus bare-metal stent versus drug-eluting stent in primary percutaneous coronary intervention with 6-month angiographic, intravascular, functional, and clinical outcomes. J Am Coll Cardiol. 2012;59(25):2327-37.

24. Chae IH, Yoon CH, Park JJ, Oh IY, Suh JW, Cho YS, Youn TJ, Choi DJ. Comparison of drug-eluting balloon followed by bare metal stent with drug-eluting stent for treatment of de novo lesions: randomized, controlled, single-center clinical trial. J Korean Med Sci. 2017;32(6):933-41.

25. Clever YP, Cremers B, Speck U, Dietz U, Böhm M, Scheller B. Influence of a paclitaxel coated balloon in combination with a bare metal stent on restenosis and endothelial function: comparison with a drug eluting stent and a bare metal stent. Catheter Cardiovasc Interv. 2014;84(2):323-31.

26. Herdeg C, Göhring-Frischholz K, Haase KK, Geisler T, Zürn C, Hartmann U, Wöhrle J, Nusser T, Dippon J, May AE, et al. Catheter-based delivery of fluid paclitaxel for prevention of restenosis in native coronary artery lesions after stent implantation. Circulation Cardiovascular interventions. 2009;2:294-301.

27. Liistro F, Porto I, Angioli P, Grotti S, Ducci K, Falsini G, Bolognese L. Elutax paclitaxel-eluting balloon followed by bare-metal stent compared with Xience $V$ drug-eluting stent in the treatment of de novo coronary stenosis: a randomized trial. Am Heart J. 2013;166(5):920-6.

28. Poerner TC, Otto S, Gassdorf J, Nitsche K, Janiak F, Scheller B, Goebel B, Jung C, Figulla HR. Stent coverage and neointimal proliferation in bare metal stents postdilated with a paclitaxel-eluting balloon versus everolimus-eluting stents: prospective randomized study using optical coherence tomography at 6-month follow-up. Circ Cardiovasc Interv. 2014;7(6):760-7.

29. Zurakowski A, Buszman PP, Milewski KP, Janas A, Gorycki B, Kondys M, Gasior P, Michalak M, Boxberger M, Peppas A, et al. Stenting and adjunctive delivery of paclitaxel via balloon coating versus durable polymeric matrix for de novo coronary lesions: clinical and angiographic results from the prospective randomized trial. J Interv Cardiol. 2015;28(4):348-57.
30. Adriaenssens T, Dens J, Ughi G, Bennett J, Dubois C, Sinnaeve P, Wiyono S, Coosemans M, Belmans A, D'Hooge J, et al. Optical coherence tomography study of healing characteristics of paclitaxel-eluting balloons vs. everolimuseluting stents for in-stent restenosis: the SEDUCE (safety and efficacy of a drug elUting balloon in coronary artery rEstenosis) randomised clinical trial. Eurolntervention. 2014;10(4):439-48.

31. Alfonso F, Perez-Vizcayno MJ, Cardenas A, Garcia del Blanco B, Garcia-Touchard A, Lopez-Minguez JR, Benedicto A, Masotti M, Zueco J, Iniguez A, et al. A prospective randomized trial of drug-eluting balloons versus Everolimuseluting stents in patients with in-stent restenosis of drug-eluting stents: the RIBS IV randomized clinical trial. J Am Coll Cardiol. 2015;66(1):23-33.

32. Alfonso F, Perez-Vizcayno MJ, Cardenas A, Garcia Del Blanco B, Seidelberger B, Iniguez A, Gomez-Recio M, Masotti M, Velazquez MT, Sanchis J, et al. A randomized comparison of drug-eluting balloon versus everolimus-eluting stent in patients with bare-metal stent-in-stent restenosis: the RIBS V clinical trial (restenosis intra-stent of bare metal stents: paclitaxel-eluting balloon vs. everolimus-eluting stent). J Am Coll Cardiol. 2014;63(14):1378-86.

33. Byrne RA, Neumann FJ, Mehilli J, Pinieck S, Wolff B, Tiroch K, Schulz S, Fusaro M, Ott I, Ibrahim T, et al. Paclitaxel-eluting balloons, paclitaxel-eluting stents, and balloon angioplasty in patients with restenosis after implantation of a drug-eluting stent (ISAR-DESIRE 3): a randomised, open-label trial. Lancet. 2013;381(9865):461-7.

34. Pleva L, Kukla P, Kusnierova P, Zapletalova J, Hlinomaz O. Comparison of the efficacy of paclitaxel-eluting balloon catheters and Everolimus-eluting stents in the treatment of coronary in-stent restenosis: the treatment of in-stent restenosis study. Circ Cardiovasc Interv. 2016;9(4):e003316.

35. Unverdorben M, Vallbracht C, Cremers B, Heuer H, Hengstenberg C, Maikowski C, Werner GS, Antoni D, Kleber FX, Bocksch W, et al. Paclitaxelcoated balloon catheter versus paclitaxel-coated stent for the treatment of coronary in-stent restenosis. Circulation. 2009;119(23):2986-94.

36. Xu B, Gao R, Wang J, Yang Y, Chen S, Liu B, Chen F, Li Z, Han Y, Fu G, et al. A prospective, multicenter, randomized trial of paclitaxel-coated balloon versus paclitaxel-eluting stent for the treatment of drug-eluting stent in-stent restenosis: results from the PEPCAD China ISR trial. JACC Cardiovascular interventions. 2014;7(2):204-11.

37. Cortese B, Micheli A, Picchi A, Coppolaro A, Bandinelli L, Severi S, Limbruno $U$. Paclitaxel-coated balloon versus drug-eluting stent during $\mathrm{PCl}$ of small coronary vessels, a prospective randomised clinical trial. The PICCOLETO study. Heart (british cardiac society). 2010;96:1291-6.

38. Latib A, Colombo A, Castriota F, Micari A, Cremonesi A, Felice F, Marchese A, Tespili M, Presbitero P, Sgueglia GA, et al. A randomized multicenter study comparing a paclitaxel drug-eluting balloon with a paclitaxel-eluting stent in small coronary vessels: the BELLO (balloon elution and late loss optimization) study. J Am Coll Cardiol. 2012;60:2473-80.

39. Ali RM, Degenhardt R, Zambahari R, Tresukosol D, Ahmad WA, Kamar H, KuiHian S, Ong TK, bin Ismail O, bin Elis S, et al. Paclitaxel-eluting balloon angioplasty and cobalt-chromium stents versus conventional angioplasty and paclitaxel-eluting stents in the treatment of native coronary artery stenoses in patients with diabetes mellitus. Eurolntervention. 2011;7(Suppl K):K83-K92.

40. Stella PR, Belkacemi A, Dubois C, Nathoe H, Dens J, Naber C, Adriaenssens T, Belle E, Doevendans P, Agostoni P. A multicenter randomized comparison of drug-eluting balloon plus bare-metal stent versus bare-metal stent versus drug-eluting stent in bifurcation lesions treated with a single-stenting technique: six-month angiographic and 12-month clinical results of the drug-eluting balloon in bifurcations trial. Catheterization and cardiovascular interventions. 2012:80:1138-46.

41. Lopez Minguez JR, Nogales Asensio JM, Doncel Vecino LJ, Sandoval J, Romany S, Martinez Romero P, Fernandez Diaz JA, Fernandez Portales J, Gonzalez Fernandez R, Martinez Caceres G, et al. A prospective randomised study of the paclitaxel-coated balloon catheter in bifurcated coronary lesions (BABILON trial): 24-month clinical and angiographic results. Eurolntervention. 2014;10(1):50-7.

42. Unverdorben $M$, Vallbracht $C$, Cremers B, Heuer $H$, Hengstenberg C, Maikowski C, Werner GS, Antoni D, Kleber FX, Bocksch W, et al. Paclitaxelcoated balloon catheter versus paclitaxel-coated stent for the treatment of coronary in-stent restenosis: the three-year results of the PEPCAD II ISR study. Eurolntervention. 2015;11(8):926-34.

43. Latib A, Ruparelia N, Menozzi A, Castriota F, Micari A, Cremonesi A, De Felice F, Marchese A, Tespili M, Presbitero P, et al. 3-year follow-up of the balloon elution and late loss optimization study (BELLO). JACC Cardiovascular interventions. 2015;8(8):1132-4. 
44. Kufner S, Cassese S, Valeskini M, Neumann FJ, Schulz-Schupke S, Hoppmann P, Fusaro M, Schunkert H, Laugwitz KL, Kastrati A, et al. Long-term efficacy and safety of paclitaxel-eluting balloon for the treatment of drug-eluting stent restenosis: 3-year results of a randomized controlled trial. JACC Cardiovascular interventions. 2015;8(7):877-84.

45. Alfonso F, Perez-Vizcayno MJ, Garcia Del Blanco B, Otaegui I, Masotti M, Zueco J, Velaquez M, Sanchis J, Garcia-Touchard A, Lazaro-Garcia R, et al. Long-term results of Everolimus-eluting stents versus drug-eluting balloons in patients with bare-metal in-stent restenosis: 3-year follow-up of the RIBS V clinical trial. JACC Cardiovascular interventions. 2016;9(12):1246-55.

46. Scheller B, Hehrlein C, Bocksch W, Rutsch W, Haghi D, Dietz U, Böhm M, Speck U. Treatment of coronary in-stent restenosis with a paclitaxel-coated balloon catheter. New England journal of medicine. 2006;355:2113-24.

47. Fröhlich GM, Lansky AJ, Ko DT, Archangelidi O, De Palma R, Timmis A, Meier P. Drug eluting balloons for de novocoronary lesions - a systematic review and meta-analysis. BMC Med. 2013;11(1):123.

48. Sinaga DA, Ho HH, Watson TJ, Sim A, Nyein TT, Jafary FH, Loh JKK, Ooi YW, Tan JKB, Ong PJL. Drug-coated balloons: a safe and effective alternative to drug-eluting stents in small vessel coronary artery disease. J Interv Cardiol. 2016;29(5):454-60

49. Naganuma T, Latib A, Costopoulos C, Oreglia J, Testa L, De Marco F, Candreva A, Chieffo A, Naim C, Montorfano M, et al. Drug-eluting balloon versus second-generation drug-eluting stent for the treatment of restenotic lesions involving coronary bifurcations. Eurolntervention. 2016;11(9):989-95.

50. Jackson D, Tong D, Layland J. A review of the coronary applications of the drug coated balloon. Int J Cardiol. 2017;226:77-86.

51. Yu CM, Kwong JS, Sanderson JE. Drug-eluting balloons for coronary artery disease: a meta-analysis of randomized controlled trials. Int J Cardiol. 2013;168(1):197-206.

52. Lu W, Zhu Y, Han Z, Wang X, Wang X, Qiu C. Drug-coated balloon in combination with bare metal stent strategy for de novo coronary artery disease: a PRISMA-compliant meta-analysis of randomized clinical trials. Medicine. 2017;96(12):e6397.

53. Zhang T, Sun S, Shen L, He B. Drug-eluting balloons for de novo coronary artery disease: a meta-analysis of angiographic and clinical data. Catheter Cardiovasc Interv. 2013;82(7):1021-30.

54. Naganuma T, Latib A, Costopoulos C, Oreglia J, Testa L, De Marco F, Bedogni F, Colombo A. Impact of drug-eluting balloon for the treatment of restenotic lesions involving coronary bifurcations. Eur Heart J. 2013;34:219.

55. Radke PW, Joner M, Joost A, Byrne RA, Hartwig S, Bayer G, Steigerwald K, Wittchow E. Vascular effects of paclitaxel following drug-eluting balloon angioplasty in a porcine coronary model: the importance of excipients. Eurolntervention. 2011;7(6):730-7.

56. Fischer D, Scheller B, Schafer A, Klein G, Bohm M, Clever Y, Cremers B. Paclitaxcel-coated balloon plus bare metal stent vs. sirolimus-eluting stent in de novo lesions: an IVUS study. Eurolntervention. 2012;8(4):450-5.

57. Dangas GD, Serruys PW, Kereiakes DJ, Hermiller J, Rizvi A, Newman W, Sudhir K, Smith Jr RS, Cao S, Theodoropoulos K, et al. Meta-analysis of Everolimus-eluting versus paclitaxel-eluting stents in coronary artery disease: final 3-year results of the SPIRIT clinical trials program (clinical evaluation of the Xience $V$ Everolimus eluting coronary stent system in the treatment of patients with de novo native coronary artery lesions). J Am Coll Cardiol Intv. 2013;6(9):914-22.

58. Baber U, Mehran R, Sharma SK, Brar S, Yu J, Suh J-W, Kim H-S, park S-J, Kastrati a, Waha d, et al. impact of the Everolimus-eluting stent on stent thrombosis: a meta-analysis of 13 randomized trials. J Am Coll Cardiol. 2011;58(15):1569-77.

59. Granada JF, Milewski K, Zhao H, Stankus JJ, Tellez A, Aboodi MS, Kaluza GL, Krueger CG, Virmani R, Schwartz LB, et al. Vascular response to Zotarolimuscoated balloons in injured superficial femoral arteries of the familial Hypercholesterolemic swine. Circulation: Cardiovascular Interventions. 2011;4(5):447-55.

60. Kleber FX, Rittger H, Bonaventura K, Zeymer U, Wöhrle J, Jeger R, Levenson B, Möbius-Winkler S, Bruch L, Fischer D, et al. Drug-coated balloons for treatment of coronary artery disease: updated recommendations from a consensus group. Clin Res Cardiol. 2013;102(11):785-97.

61. Onuma Y, Ormiston J, Serruys PW. Bioresorbable scaffold technologies. Circ J. 2011:75(3):509-20
62. Wöhrle J, Markovic S, Rottbauer W, Muramatsu T, Kadota K, Vázquez-González N, Odenstedt J, Serra A, Antoniucci D, Varenne O, et al. Bioresorbable polymer sirolimus-eluting coronary stent compared with permanent polymer everolimuseluting coronary stent implantation for treatment of small vessel coronary artery disease: CENTURY II trial. Eurolntervention. 2016;12(2):e167-e174.

63. Mahmoud AN, Barakat AF, Elgendy AY, Schneibel E, Mentias A, Abuzaid A, Elgendy IY. Long-term efficacy and safety of Everolimus-eluting Bioresorbable vascular scaffolds versus Everolimus-eluting metallic stents: a meta-analysis of randomized trials. Circulation: Cardiovascular Interventions. 2017;10(5);e005286.

\section{Submit your next manuscript to BioMed Central and we will help you at every step:}

- We accept pre-submission inquiries

- Our selector tool helps you to find the most relevant journal

- We provide round the clock customer support

- Convenient online submission

- Thorough peer review

- Inclusion in PubMed and all major indexing services

- Maximum visibility for your research

Submit your manuscript at www.biomedcentral.com/submit 